\title{
Ultrathin films of 2D Hofmann-type coordination polymers: influ- ence of pillaring linkers on structural flexibility and vertical charge transport
}

\author{
Víctor Rubio-Giménez, ${ }^{+}$Garin Escorzia-Ariza, ${ }^{\dagger}$ Carlos Bartual-Murgui, ${ }^{+}$Christian Sternemann, ${ }^{\ddagger}$ Marta Gal- \\ biati, ${ }^{+, a}$ Javier Castells-Gil, ${ }^{+}$José Antonio Real, ${ }^{+}$Sergio Tatay ${ }^{+, *}$ and Carlos Martí-Gastaldo ${ }^{+, *}$ \\ † Instituto de Ciencia Molecular, Universitat de València, Catedrático José Beltrán 2, 46980 Paterna, Spain \\ ${ }^{\ddagger}$ Fakultät Physik/DELTA, Technische Universität Dortmund, 44221 Dortmund, Germany
}

\begin{abstract}
Searching for novel materials and controlling their nanostructuration into electronic devices is a challenging task ahead of chemists and chemical engineers. Even more so when this new application requires an exquisite control over the morphology, crystallinity, roughness and orientation of the films produced. In this context, it is of critical importance to analyze the influence of the chemical composition of perspective materials on their properties at the nanoscale. We report the fabrication of ultrathin films (thickness $<30 \mathrm{~nm}$ ) of a family of $\mathrm{Fe}^{\mathrm{II}} \mathrm{Hofmann}^{-l i k e}$ coordination polymers by using an optimized liquid phase epitaxy $(\mathrm{LPE})$ set-up. The series $\left[\mathrm{Fe}(\mathrm{L})_{2}\left\{\mathrm{Pt}(\mathrm{CN})_{4}\right\}\right](\mathrm{L}=$ pyridine, pyrimidine and isoquinoline) conform an ideal platform for correlating the effect of the axial nitrogenated ligand with changes to their structural response to guests or electrical resistance. All film properties relevant to device integration have been thoroughly analyzed with complementary surface techniques for a meaningful comparison. Our results reveal that changes to this ligand can hinder the structural transformation triggered by the absorption of guest molecules previously reported for the pyridine phase. Also important, it can substantially hinder vertical charge transport across the layers, even at the ultrathin film limit.
\end{abstract}

\section{INTRODUCTION}

Metal-organic frameworks (MOFs) and coordination polymers (CPs) are on the path of being included in functional electronic devices as electroactive and stimuli-responsive materials. ${ }^{1-3}$ These crystalline frameworks, formed by the periodic assembly of metal ions and polytopic organic ligands, offer an attractive and versatile platform with an almost endless variety of molecular pieces, to construct materials with tunable structural and electronic properties. However, the path to integrate them in actual devices calls for their processing into ultrathin films with exquisite control over several factors that can influence device performance. Film thickness, substrate coverage, homogeneity, roughness, crystallinity or the orientation of the film with respect to the substrate have to be carefully controlled to achieve a viable device. Polycrystalline films built from electrochemical or direct solvothermal synthesis often do not meet these standards. ${ }^{4,5}$ In turn, the substrate transfer of nanofilms formed at the air-liquid or liquid-liquid interfaces and the Layer-by-Layer (LbL) deposition directly onto the substrate are more suitable to produce crystalline ultrathin films of MOFs and CPs, more respectful with the above parameters. ${ }^{6-8}$

A particular case of LbL is LPE, that is when a chemicallyfunctionalized substrate is sequentially immersed in diluted solutions of the metal ions and organic ligands of the targeted CP. LPE permits a high control over the crystalline orientation, imposed by the surface anchoring group, and film thickness as it involves a selflimiting coordination reaction. Moreover, it even enables to produce $\mathrm{CPs}$ that are inaccessible in the bulk form and film heterostructures with smooth interfaces. ${ }^{9,10} \mathrm{LPE}$ has been a powerful resource to grow thin films of $\mathrm{Fe}^{\mathrm{II}}$-spin crossover (SCO) frameworks, for which the LPE approach constitutes an interesting alternative to vacuum sublimation of molecular SCO complexes. ${ }^{11-15}$ The technological prospects for these materials are linked to the ability of the $\mathrm{Fe}^{\mathrm{II}}$ centers to switch between the diamagnetic low-spin (LS) and paramagnetic high-spin (HS) electronic configurations. This can be triggered with a variety of external inputs like temperature, light, pressure, guest analytes and magnetic or electric fields. ${ }^{16-22}$ From an electronic point of view, the HS to LS reversible switching can be exploited in memory devices. In fact, various studies have shown potential using SCO nanoparticles and single molecules. ${ }^{23-27}$ Thus making SCO materials ideal for their integration in multifunctional electronic and spintronic devices. ${ }^{22,28}$ Given the low conductivity generally displayed by $\mathrm{Fe}^{\mathrm{II}} \mathrm{SCO}$ materials, ${ }^{29}$ their integration into electronic devices generally requires their deposition as ultrathin films (tens of nanometers) and small electrode separations to make them conductive enough to withstand the pass of electrical current, and simultaneously maintain their SCO properties at the ultrathin level.

One particularly interesting family of SCO CPs is $\mathrm{Fe}^{\mathrm{II}}$ Hofmann-like CPs (Fe ${ }^{\mathrm{II}}$-HCPs). ${ }^{30,31} \mathrm{Fe}^{\mathrm{II}}$-HCPs are composed by metal-cyanide-metal layers with formula $\left[\mathrm{Fe}(\mathrm{L})_{\mathrm{x}}\left\{\mathrm{Pt}(\mathrm{CN})_{4}\right\}\right](\mathrm{x}=1$ $2),{ }^{32}$ vertically separated by aromatic nitrogen-based pillaring ligands $(\mathrm{L})$ coordinated to octahedral $\mathrm{Fe}^{\mathrm{II}}$ metal ions. Depending on the connectivity of these ligands, they can form either $2 \mathrm{D}(\mathrm{x}=1)$ or $3 \mathrm{D}(\mathrm{x}=2)$ structures (see Figure SI1). The latter display intrinsic porosity due to the $1 \mathrm{D}$ channels that run parallel to the metal-cyanide planes, while the former are not intrinsically porous in the bulk 
a)

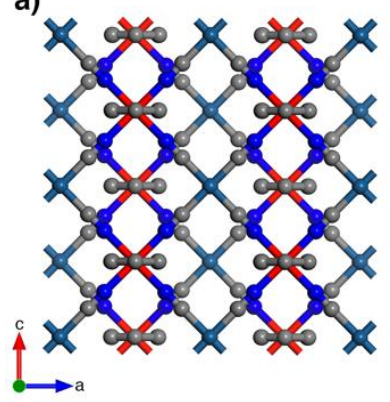

b)



c)

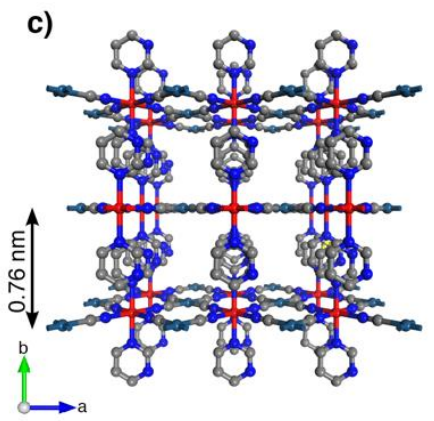

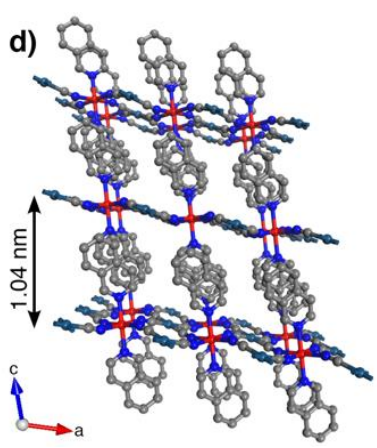

Figure 1. Structure of the $\left[\mathrm{Fe}(\mathrm{L})_{2}\left\{\mathrm{Pt}(\mathrm{CN})_{4}\right\}\right]$ family. a) Perspective of the metal-cyanide layer along the $\mathrm{b}$ axis in $\left[\mathrm{Fe}(\mathrm{py})_{2}\left\{\mathrm{Pt}(\mathrm{CN})_{4}\right\}\right]$. Side views along the a axis of $\left[\mathrm{Fe}(\mathrm{py})_{2}\left\{\mathrm{Pt}(\mathrm{CN})_{4}\right\}\right](\mathrm{b}),\left[\mathrm{Fe}(\mathrm{pym})_{2}\left\{\mathrm{Pt}(\mathrm{CN})_{4}\right\}\right](\mathrm{c})$ and $\left[\mathrm{Fe}(\mathrm{isoq})_{2}\left\{\mathrm{Pt}(\mathrm{CN})_{4}\right\}\right](\mathrm{d})$ showing the planar $(\mathrm{b}$ and $\mathrm{c})$ and corrugated (d) layers vertically stacked together thanks to $\pi-\pi$ interactions between the pillaring ligands. Interlayer separation considerably increases from 0.76 $\mathrm{nm}$ for $\mathrm{L}=\mathrm{py}(\mathrm{b})$ and pym (c), up to $1.04 \mathrm{~nm}$ for isoq (d). Color code: Fe, red; Pt, turquoise; N, blue; C, grey.

form as their monodentate pillaring ligands yield interdigitated structures due to $\pi-\pi$ interactions. As demonstrated by Mallouk, Bousseksou, Kitagawa and their respective collaborators, processing $3 \mathrm{D} \mathrm{Fe}{ }^{\mathrm{II}}$-HCPs into thin films using the LPE methodology requires temperatures of at least $-60^{\circ} \mathrm{C}$, low enough to prevent the disassembly of the $\mathrm{Fe}^{\mathrm{II}}$ ions during the epitaxial process, ${ }^{33-35}$ whereas films of their $2 \mathrm{D}$ counterparts can be grown at room temperature. ${ }^{33,35-38} \mathrm{By}$ employing an optimized LPE procedure, we recently demonstrated that the SCO transition in $\left[\mathrm{Fe}(\mathrm{py})_{2}\left\{\mathrm{Pt}(\mathrm{CN})_{4}\right\}\right]$ (py = pyridine), a $2 \mathrm{D} \mathrm{Fe}{ }^{\mathrm{II}}$ - $\mathrm{HCP}$, is retained when processed as ultrathin films. ${ }^{39}$ Moreover, in a previous report, Kitagawa and co-workers showed the appearance of an unprecedented gate-opening response to guests in this material for films of comparable thickness. ${ }^{40}$ Motivated by this phenomena and the perspective of integrating these materials into responsive electronic devices, we decided to prepare a family of $2 \mathrm{D}$ $\mathrm{Fe}^{\mathrm{II}}-\mathrm{HCPs}$ with py and two alternative pillaring ligands (Figure 1): pyrimidine (pym) and isoquinoline (isoq). Replacement of the axial nitrogenated ligand whilst keeping the same metal-cyanide layers provides an excellent platform for analyzing the effect of the pillaring linker on the vertical charge transport and structural properties of this family of $2 \mathrm{D}$ CPs at the nanoscale.

\section{EXPERIMENTAL SECTION}

Materials and methods. Iron(II) tetrafluoroborate hexahydrate $\left(\mathrm{Fe}\left(\mathrm{BF}_{4}\right)_{2} \cdot 6 \mathrm{H}_{2} \mathrm{O}\right)$ (Sigma-Aldrich, 97\%), anhydrous pyridine (py) (Sigma-Aldrich, $\geq 99 \%$ ), pyrimidine (pym) (Sigma-Aldrich, $\geq 98 \%$ ), isoquinoline (isoq) (Sigma-Aldrich, >97\%), 4-mercaptopyridine (py-SH) (TCI, >97\%), tetrabutylammonium bromide (TBABr) (Sigma-Aldrich, $\geq 98 \%$ ), potassium tetracyanoplatinate(II) hydrate $\left.\left(\mathrm{K}_{2} \mathrm{Pt}(\mathrm{CN})_{4}\right) \cdot \mathrm{xH}_{2} \mathrm{O}\right)$ (Strem Chemicals, 95\%) and Gallium-Indium (Ga-In) eutectic (Sigma-Aldrich, $\geq 99.99 \%$ ) were used as received without further purification. Anhydrous ethanol (99.5\%) was purchased from Acros Organics. Other solvents (HPLC-grade) were purchased from Scharlab S.L. (TBA $)_{2} \operatorname{Pt}(\mathrm{CN})_{4}$ was synthesized following a literature procedure. ${ }^{30}$

Substrate preparation and SAM functionalization. Prior to $\mathrm{Au}$ evaporation, substrates were soaked in a freshly prepared solution of $\mathrm{H}_{2} \mathrm{O}_{2} / \mathrm{NH}_{4} \mathrm{OH} / \mathrm{H}_{2} \mathrm{O}(1: 1: 2)$ and sonicated for $10 \mathrm{~min}$. This treatment was repeated three times. Next, they were rinsed with Milli-Q water, sonicated 5 min in Milli-Q water twice, and dried under a stream of $\mathrm{N}_{2}$. Then, metal evaporation was performed in an Edwars Auto 500 thermal evaporator placed inside a $\mathrm{N}_{2}$-filled glovebox.
The base pressure and evaporation rate were $2 \cdot 10^{-6} \mathrm{mbar}$ and $0.2 \AA$. ${ }^{1}$ respectively. $15 \mathrm{~nm}$ of $\mathrm{Au}$ onto $\mathrm{SiO}_{2}$ (native)/Si substrates was the preferred thickness except for infrared spectroscopy studies for which $150 \mathrm{~nm}$ of Au onto glass substrates (Soda-lime) were used instead. $3 \mathrm{~nm}$ of Ti were used as adhesion layer in all cases. For SAM functionalization, $\mathrm{Au}$ substrates were previously activated via $\mathrm{O}_{2}$ plasma treatment (MiniPCFlecto, Plasma Technology) and then immersed in a $1 \mathrm{mM}$ ethanol solution of py-SH for $24 \mathrm{~h}$. Next, substrates were rinsed with fresh ethanol and dried under a stream of $\mathrm{N}_{2}$.

LPE fabrication of $\left[\mathrm{Fe}(\mathrm{L})_{2}\left\{\mathrm{Pt}(\mathrm{CN})_{4}\right\}\right]$ ultrathin films. Films were prepared according to the reported methodology. ${ }^{39} \mathrm{Au}$ substrates functionalized with a py-SH SAM were sequentially immersed in anhydrous ethanol solutions containing a mixture of the corresponding metal complexes and $\mathrm{L}$ or pure anhydrous ethanol. In the case of $\mathrm{L}=$ py we used $10 \mathrm{mM} \mathrm{Fe}\left(\mathrm{BF}_{4}\right)_{2} / 100 \mathrm{mM} \mathrm{L}$ and $10 \mathrm{mM}$ $(\mathrm{TBA})_{2} \mathrm{Pt}(\mathrm{CN})_{4} / 100 \mathrm{mM} \mathrm{L}$ mixtures whereas in the case of $\mathrm{L}=$ isoq and pym we used $25 \mathrm{mM} \mathrm{Fe}\left(\mathrm{BF}_{4}\right)_{2} / 100 \mathrm{mM} \mathrm{L}$ and $25 \mathrm{mM}$ (TBA $)_{2} \mathrm{Pt}(\mathrm{CN})_{4} / 100 \mathrm{mM} \mathrm{L}$ solutions. Immersion time was $3 \mathrm{~min}$ in each solution with intermediate washing steps of $1 \mathrm{~min}$ in pure anhydrous ethanol. The LPE sequential immersion was performed using a KSV automatic dipping system placed in a $\mathrm{N}_{2}$-filled glovebox at room temperature. After the final intended number of immersion cycles was completed, substrates were dried under a stream of $\mathrm{N}_{2}$.

\section{Physical characterization.}

Powder X-ray diffraction (PXRD). Patterns for bulk were collected from polycrystalline samples using a high-throughput screening platform in a PANalytical Empyrean diffractometer in transmission mode, operating at $40 \mathrm{~mA}$ and $45 \mathrm{kV}$ using copper radiation $(\mathrm{Cu} \mathrm{K \alpha}$ $=1.5418 \AA$ ) and a PIXcel detector. Profiles were collected by using a Soller Slit of $0.02^{\circ}$ and a divergence slit of $1 / 4$ at room temperature in the angular range $3^{\circ}<2 \theta<50^{\circ}$ with a step size of $0.013^{\circ}$. LeBail refinements were carried out withthe FULLPROF software package. $^{41}$

Elemental CHNSO analysis. CHNSO analysis was performed using a FlashSmart (Thermofisher) elementary analyzer with a thermal conductivity detector. Helium and oxygen (both purity 99.995\%) were used as the carrier and combusting gases, respectively. The combustion tube was set up at $950^{\circ} \mathrm{C}$ and the reduction tube at $600^{\circ}$ C. Sulfanilamide was used as CHNS standard. 
Infrared reflection absorption spectroscopy (IRRAS). Measurements were performed on a VeeMax II sampling stage (Pike Technologies) placed in the sample compartment of a Nicolet 5700 Transformation-Infrared Spectrometer. All measurements were performed under nitrogen atmosphere. Each FT-IR spectrum represents the average of 512 scans at $4 \mathrm{~cm}^{-1}$ resolution. The infrared beam (incidence angle: $75^{\circ}$ ) was p-polarized by mean of a manual $\mathrm{ZnSe}$ polarizer and the output signal was collected using a refrigerated mercury cadmium telluride detector.

Atomic force microscopy (AFM). Measurements were performed with a Digital Instruments Veeco Nanoscope IVa microscope in tapping mode using $\mathrm{Si}$ tips with a natural resonance frequency of 300 $\mathrm{KHz}$ and with an equivalent constant force of $40 \mathrm{~N} \cdot \mathrm{m}^{-1}$. Scan rate was adjusted during the scanning of each image and kept in between 0.1$1 \mathrm{~Hz}$. Resolution for all images was 512 points/line. Film thickness was evaluated by scratching off the $2 \mathrm{D} \mathrm{Fe}{ }^{\mathrm{II}}-\mathrm{HCP}$ film using a toothpick.

X-ray Photoelectron Spectroscopy (XPS). Spectra were collected at the X-ray Spectroscopy Service of the Universitat d'Alacant using a K-Alpha X-ray photoelectron spectrometer system (Thermo Scientific). All spectra were collected using Al $\mathrm{Ka}$ radiation $(1486.6 \mathrm{eV})$, monochromatized by a twin crystal monochromator, yielding a focused X-ray spot (elliptical in shape with a major axis length of 400 $\mu \mathrm{m})$ at $3 \mathrm{~mA} \cdot \mathrm{C}$ and $12 \mathrm{kV}$. The Alpha hemispherical analyzer was operated in the constant energy mode with survey scan pass energies of $200 \mathrm{eV}$ to measure the whole energy band and $50 \mathrm{eV}$ in a narrow scan to selectively measure the particular elements. XPS data were analyzed with Avantage software. A smart background function was used to approximate the experimental backgrounds. Charge compensation was achieved with the system flood gun that provides low energy electrons and low energy argon ions from a single source. Spectra are referenced using the $\mathrm{C} 1 \mathrm{~s}$ main peak $(285.0 \mathrm{eV})$.

Synchrotron Grazing Incidence X-ray Diffraction (GIXRD). Measurements were performed at beamline BL9 of DELTA synchrotron. ${ }^{40}$ Samples were placed into a closed cell mounted on a multiaxis diffractometer and measured under a continuous He flow. Single shot images (100 seconds exposition) were recorded at room temperature using a MAR area detector with a wavelength of 0.8266 $\AA$ (15 keV incident energy), a sample-to-detector distance of 352 $\mathrm{mm}$ (calibrated with $\mathrm{LaB}_{6}$ reference sample) at angle of incidence of $0.1^{\circ}$ with a beam size of $1 \times 0.2 \mathrm{~mm}^{2}$. Data was analyzed and processed using FIT2D software. ${ }^{41,42}$ For the in-situ XRD measurements under solvent vapors, the closed sample cell was connected to a custom-built He gas flow system capable of semi-quantitatively controlling the relative pressure of solvent vapor into the sample cell. See Supporting Information for more details. Out-of-plane diffractograms were measured in scanning mode at room temperature $\left(25^{\circ}\right.$ C) using a Pilatus $100 \mathrm{~K}$ detector.

Solvent sorption measurements. Measurements were performed on freshly made bulk samples after activation in an Autosorb station at and $10^{-6}$ Torr at $100{ }^{\circ} \mathrm{C}$ prior to analysis. Methanol adsorption-desorption isotherms were recorded at $298 \mathrm{~K}$ on a Micromeritics 3Flex apparatus.

Electrical Characterization. Log J histograms were obtained from the analysis of the current (I) as function of the applied bias (V, GaIn eutectic drop biased positively) curves recorded after bringing a Ga-In eutectic drop into contact with the surface of the
$\left[\mathrm{Fe}(\mathrm{L})_{2}\left\{\mathrm{Pt}(\mathrm{CN})_{4}\right\}\right]$ films and using the $\mathrm{Au}$ film as bottom electrode. The area of the contact was estimated from the diameter of the contact zone measured using a CCD camera. Data was recorded using a Keithley 6517B electrometer and Yokogawa GS200 voltage source controlled with Labview (National Instruments). Ga-In eutectic drops with a radius of $\sim 0.3$ to $\sim 1.2 \mu \mathrm{m}^{2}$ were reproducibly produced using a syringe and a micromanipulator. See Supporting Information for more details.

\section{RESULTS AND DISCUSSION}

2D Fe"-HCPs in the bulk phase. Although the SCO properties of $\left[\mathrm{Fe}(\mathrm{pym})_{2}\left\{\mathrm{Pt}(\mathrm{CN})_{4}\right\}\right]$ and $\left[\mathrm{Fe}(\text { isoq })_{2}\left\{\mathrm{Pt}(\mathrm{CN})_{4}\right\}\right]$ in the bulk and thin film textures will be detailed in a subsequent work, here we will anticipate their structural features essential to this manuscript. Single crystals of $\left[\mathrm{Fe}(\mathrm{pym})_{2}\left\{\mathrm{Pt}(\mathrm{CN})_{4}\right\}\right]$ and $\left[\mathrm{Fe}(\text { isoq })_{2}\left\{\mathrm{Pt}(\mathrm{CN})_{4}\right\}\right]$ were prepared by controlled liquid-liquid diffusions of a $\mathrm{Fe}^{\mathrm{II}}$ salt and pym or isoq solution, into one of $\left\{\mathrm{Pt}(\mathrm{CN})_{4}\right\}^{2-}$. Their structures in the HS state, solved via single-crystal $\mathrm{X}$-ray diffraction analysis, are summarized in Figure 1. The structure of $\left[\mathrm{Fe}(\mathrm{pym})_{2}\left\{\mathrm{Pt}(\mathrm{CN})_{4}\right\}\right]$ (CCDC 1910989) is analogous to the already described py framework, ${ }^{40}$ with an equivalent interlayer distance between planar metalcyanide-metal layers. However, in $\left[\mathrm{Fe}(\text { isoq })_{2}\left\{\mathrm{Pt}(\mathrm{CN})_{4}\right\}\right](\mathrm{CCDC}$ 1910991) these layers are corrugated along the a axis, and the introduction of a bulkier ligand causes the interlayer distance to increase from $\sim 0.76 \mathrm{~nm}$ up to $\sim 1.04 \mathrm{~nm}$, that is close to a $40 \%$ expansion. Supramolecular $\pi-\pi$ interactions are responsible for the stacking of the layers in an interdigitated fashion in all cases. The distances between neighboring py, pym and isoq units in consecutive layers oscillate around $\sim 3.8 \AA$ (Table SI1 and SI2). Finally, the purity of bulk samples used thereof as references for the chemical and physical characterization of the ultrathin film samples were previously confirmed with PXRD (Figure SI2 and Table SI3) and elemental analysis (Table SI4).

Sequential growth of ultrathin films of a family of 2D Fe"HCPs under inert atmosphere. We prepared ultrathin films of the series $\left[\mathrm{Fe}(\mathrm{L})_{2}\left\{\mathrm{Pt}(\mathrm{CN})_{4}\right\}\right](\mathrm{L}=$ py, pym and isoq) by following a LPE procedure schematized in Figure 2. This method consists in the sequential immersion of Au substrates functionalized with a 4-

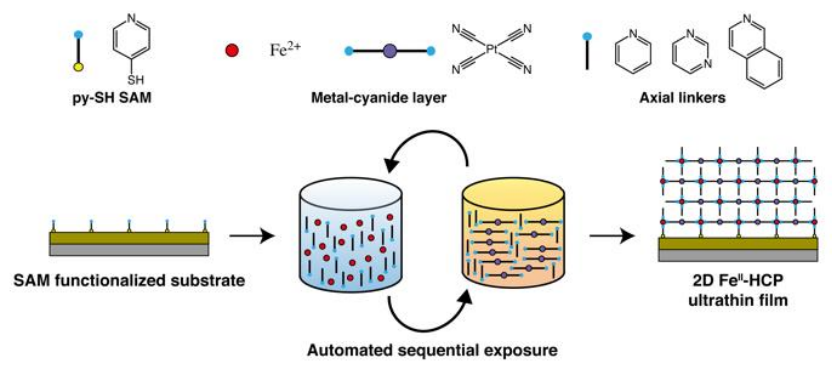

Figure 2. Automated LPE ultrathin film fabrication process of $\left[\mathrm{Fe}(\mathrm{L})_{2}\left\{\mathrm{Pt}(\mathrm{CN})_{4}\right\}\right]$. Scheme detailing the structure of the films and the LPE process with the four different molecular components of $\left[\mathrm{Fe}(\mathrm{L})_{2}\left\{\mathrm{Pt}(\mathrm{CN})_{4}\right\}\right]$ : the axial ligands, the $\left[\mathrm{Pt}(\mathrm{CN})_{4}\right]^{2-}$ complex, the $\mathrm{Fe}^{\mathrm{II}}$ ions and the py-SH SAM. A SAM-functionalized $\mathrm{Si} / \mathrm{Au}$ substrate is sequentially immersed in ethanol solutions of the molecular components, first $\mathrm{Fe}^{\mathrm{II}} / \mathrm{L}$ and then $\left[\mathrm{Pt}(\mathrm{CN})_{4}\right]^{2-} / \mathrm{L}$ with intermediate washing steps of pure ethanol. Sequential cycling for controllable film thickness is done with an automatic dipping system to ensure reproducibility. The whole process is carried out inside the glovebox to avoid $\mathrm{Fe}^{\mathrm{II}}$ oxidation. 

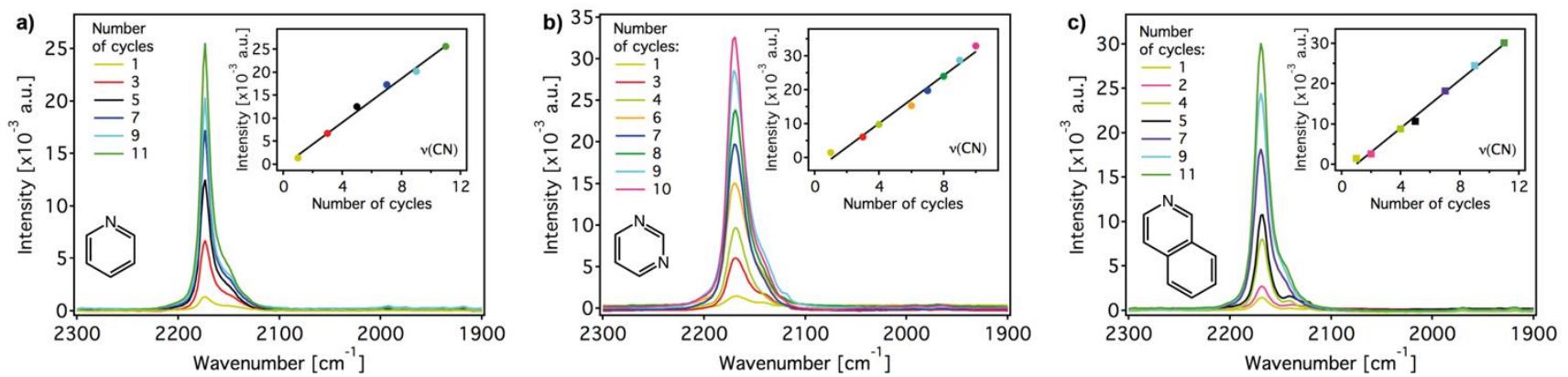

Figure 3. IRRAS characterization of $\left[\mathrm{Fe}(\mathrm{L})_{2}\left\{\mathrm{Pt}(\mathrm{CN})_{4}\right\}\right]$ ultrathin films as a function of the number of immersion cycles. Maximum absorbance of the most intense IRRAS peak, $v(\mathrm{CN})$ versus the number of cycles for $\mathrm{L}=$ py $(\mathrm{a})$, pym $(\mathrm{b})$ and isoq $(\mathrm{c})$. Data has been fitted to a linear model (black line).

mercaptopyridine (py-SH) self-assembled monolayer (SAM) in ethanol solutions of $\mathrm{Fe}\left(\mathrm{BF}_{4}\right)_{2}$ and $(\mathrm{TBA})_{2} \mathrm{Pt}(\mathrm{CN})_{4}$ with an excess of the respective axial ligand and intermediate ethanol rinsing steps to wash unreacted reagents. As previously reported, ${ }^{39}$ the use of an automated multi-vessel dip coater is a powerful tool to perform the process in a systematic and reproducible manner. Moreover, as previously mentioned, the possibility of growing $2 \mathrm{D} \mathrm{Fe}^{\mathrm{II}}-\mathrm{HCPs}$ at room temperature allows for the LPE process to undergo under an inert atmosphere in a $\mathrm{N}_{2}$-filled glovebox. This along with the use of anhydrous de-oxygenated ethanol, ensures the absence of any $\mathrm{Fe}^{\mathrm{II}}$ oxidation (see below). The presence of undesired $\mathrm{Fe}^{\mathrm{III}}$ species can substantially alter the electronic and magnetic properties of the system, negatively affecting the charge transport across the framework.

To confirm the successful growth of the $2 \mathrm{D}$ Fe ${ }^{\mathrm{II}}$-HCP ultrathin films, we checked that the infrared reflection absorption spectroscopy (IRRAS) spectra of all three 2D Fe ${ }^{\mathrm{II}}$-HCPs matched with their respective bulk FT-IR spectra (Figure SI3). This ensures the presence of $\left[\mathrm{Fe}(\mathrm{L})_{2}\left\{\mathrm{Pt}(\mathrm{CN})_{4}\right\}\right]$ in the films regardless of the pillaring linker and rules out the co-deposition of starting materials or the presence of spurious $\mathrm{Fe}^{\mathrm{III}}-\mathrm{CN}$ species. ${ }^{42}$ Furthermore, the sequential nature of the growth process is confirmed by the linear increase of the intensity of the $\mathrm{CN}$ vibrations at $2173(\mathrm{~L}=\mathrm{py}), 2170$ ( $\mathrm{L}=$ pym $)$ and $2167(\mathrm{~L}=$ isoq $) \mathrm{cm}^{-1}$, as well as the stretching bands of the aromatic rings in the axial linkers $\left(1600-1000 \mathrm{~cm}^{-1}\right)$ (Figure 3) after every immersion cycle $\left(\mathrm{Fe}^{\mathrm{II}}\right.$ - L/ethanol/ $\left[\mathrm{Pt}(\mathrm{CN})_{4}\right]^{2-}$ $\mathrm{L} / \mathrm{ethanol}$ ). This points to a growth mechanism dominated by the controlled nucleation of 2D metal-cyanide layers, which are then interdigitated in the three-dimensions by the weak interactions between neighboring nitrogenated linkers in the axial positions of the $\mathrm{Fe}^{\mathrm{II}}$ center.

The chemical purity of the films was further established by using XPS. The peaks of the constitutive elements ( $\mathrm{Fe}, \mathrm{Pt}, \mathrm{C}$ and $\mathrm{N}$ ) are visible in the survey spectra of the $\left[\mathrm{Fe}(\mathrm{L})_{2}\left\{\mathrm{Pt}(\mathrm{CN})_{4}\right\}\right]$ bulk and ultrathin film samples (Figure SI4). The high-resolution Fe $2 p$ and $\mathrm{Pt} 4 \mathrm{f}$ photoelectron spectra of the three films as a function of the number of cycles are shown in Figure 4. They all share similar spectral shapes and show main $\mathrm{Fe}\left(2 \mathrm{p}_{3 / 2}\right)$ and $\mathrm{Pt}\left(4 \mathrm{f}_{7 / 2}\right)$ peaks with weaker $\mathrm{Fe}\left(2 \mathrm{p}_{1 / 2}\right)$ and $\mathrm{Pt}\left(4 \mathrm{f}_{5 / 2}\right)$ peaks, see Table SIS for the exact peak posi-
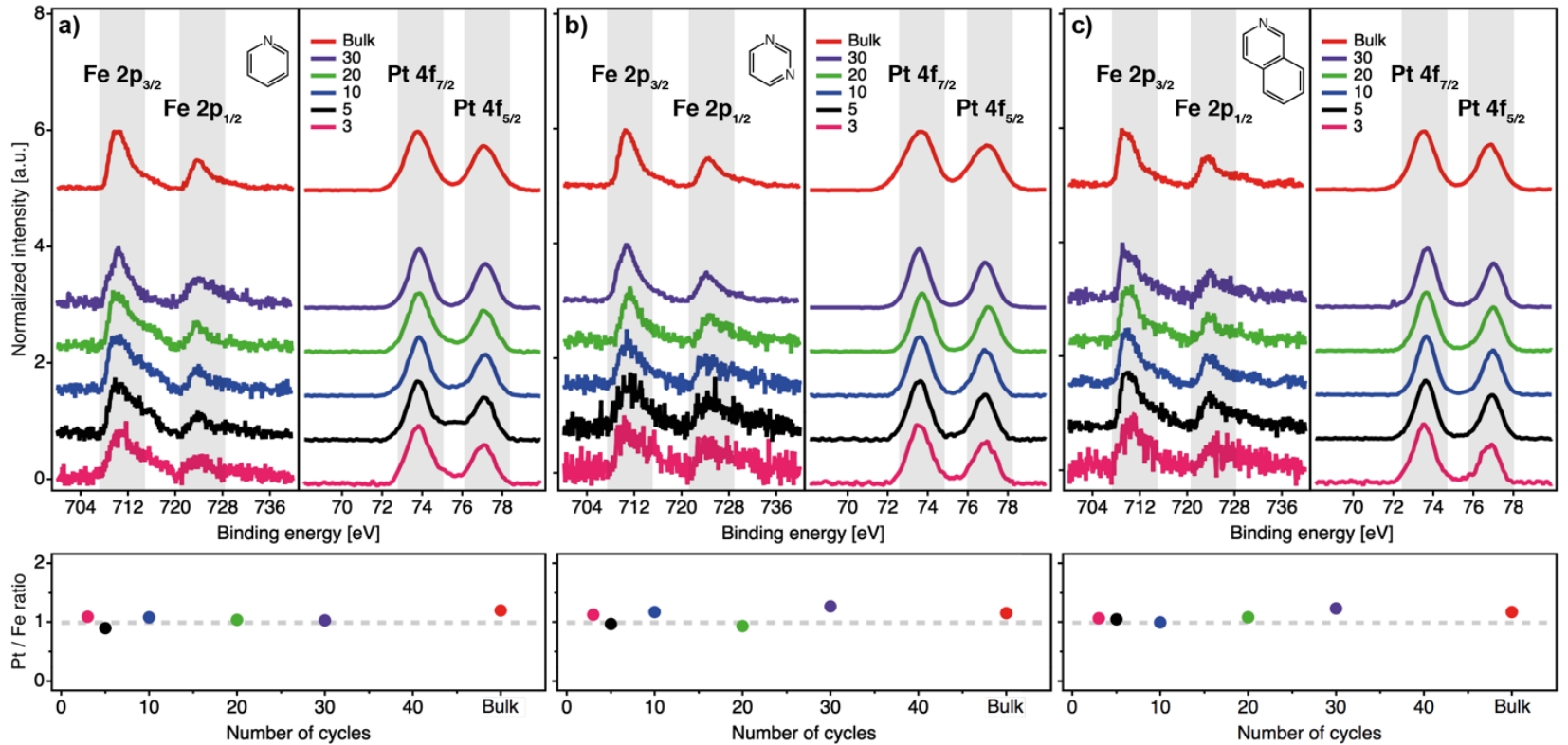

Figure 4. XPS characterization of $\left[\mathrm{Fe}(\mathrm{L})_{2}\left\{\mathrm{Pt}(\mathrm{CN})_{4}\right\}\right]$ ultrathin films as a function of the number of immersion cycles. High-resolution XPS spectra of the Fe $2 \mathrm{p}$ and $\mathrm{Pt} 4 \mathrm{f}$ regions for a set of films and bulk samples for $\mathrm{L}=\mathrm{py}(\mathrm{a}), \mathrm{pym}(\mathrm{b})$ and isoq (c). The Pt/Fe ratio (below) remains almost constant and is consistent with the theoretical value (dashed grey line) for successive immersion cycles in all cases. 

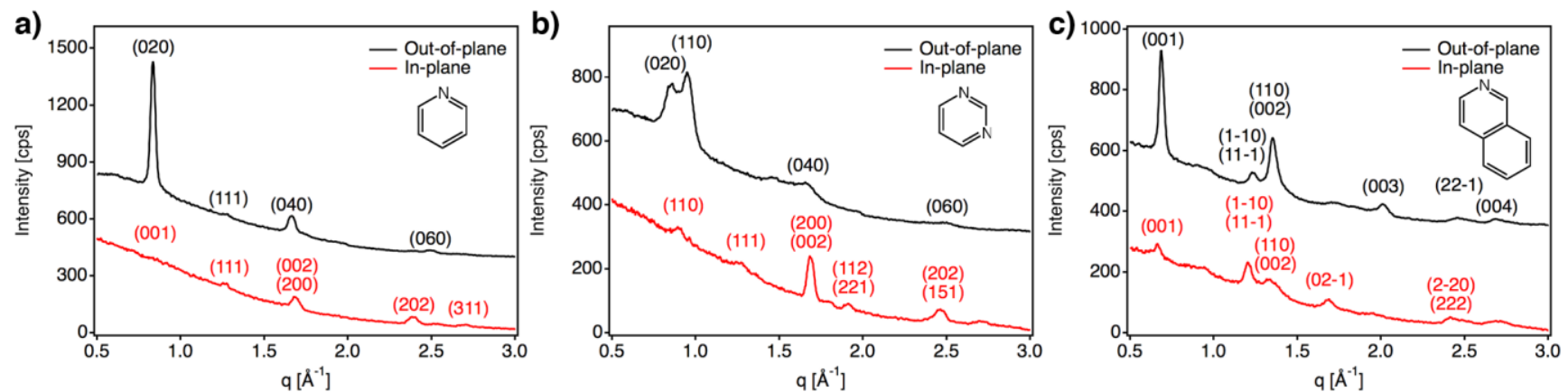

Figure 5. Structural characterization of $\left[\mathrm{Fe}(\mathrm{L})_{2}\left\{\mathrm{Pt}(\mathrm{CN})_{4}\right\}\right]$ ultrathin films. Out-of-plane and in-plane patterns as extracted from $2 \mathrm{D}-\mathrm{GIXRD}$ images for a set of 30-cycle films of $L=$ py (a), pym (b) and isoq (c).

tions along with spin orbit splittings and peak widths for representative $\mathrm{Fe} 2 \mathrm{p}$ peaks. These values and the presence of satellites above the main lines agree with the presence of $\mathrm{Fe}^{\mathrm{II}}$ in the $\mathrm{HS}$ state as observed for other $\mathrm{Fe}^{\mathrm{II}} \mathrm{SCO}$ compounds and $\mathrm{Fe}^{\mathrm{II}}$-HCPs. ${ }^{43,44}$ Likewise, our previous X-ray absorption spectroscopy (XAS) measurements of comparable $\left[\mathrm{Fe}(\mathrm{py})_{2}\left\{\mathrm{Pt}(\mathrm{CN})_{4}\right\}\right]$ ultrathin films also pointed to the absence of $\mathrm{Fe}^{\mathrm{III}}$ when using the same LPE procedure under an inert atmosphere. ${ }^{37}$ Equivalently, the high-resolution $\mathrm{Pt}$ 4f spectra points to the presence of $\mathrm{Pt}^{\mathrm{II}}$ in both thin film and bulk materials. We also quantified the amount of $\mathrm{Pt}, \mathrm{Fe}, \mathrm{N}$ and $\mathrm{C}$ for the whole series of ultrathin film samples and for the bulk materials by peak area integration. In all cases the $\mathrm{Fe} / \mathrm{Pt}$ ratio is close to the value of $1: 1$ given by the chemical formula regardless of the number of immersion cycles (Figure 4). The metal-to-ligand ratio is also within the expected chemical formula, as N/Fe ratios are also close to the respective theoretical values (Figure SI5). The good agreement between IRRAS and XPS data highlights the versatility and consistency of our LPE procedure, as it can be used to produce chemically pure ultrathin films across micrometric areas of $2 \mathrm{D} \mathrm{Fe}^{\mathrm{II}}$-HCPs, regardless of the nitrogenated axial linkers.

Preferential orientation and controllable thickness. Next, we moved on to study the crystallinity and crystalline orientation of the $\left[\mathrm{Fe}(\mathrm{L})_{2}\left\{\mathrm{Pt}(\mathrm{CN})_{4}\right\}\right]$ ultrathin films. For that we performed GIXRD measurements at beamline BL9 of DELTA synchrotron $(\lambda=0.8266$ $\AA$, room temperature $)$. Diffraction patterns were collected for 30-cycles films ( $22 \mathrm{~nm}$ thick, see below $)$ in single shot real-space image using an area detector (Figure SI6). Next, complete, in-plane and out-of-plane diffraction profiles were extracted for each $2 \mathrm{D} \mathrm{Fe}{ }^{\mathrm{II}}$ HCP and peaks were indexed following simulated diffraction patterns obtained from their crystal structures. Firstly, comparison of the complete integration GIXRD patterns with their respective bulk PXRD and simulated (without preferred orientation) diffractograms (Figure SI7) showed the presence of the most intense reflections. Regarding preferential orientation of the $2 \mathrm{D} \mathrm{Fe} \mathrm{F}^{\mathrm{II}}$ HCP layers, Figure $\mathbf{5 a}, \boldsymbol{b}$ clearly shows that out-of-plane diffractograms for $\mathrm{L}=$ py (a) and pym (b) both films present intense (0k0)
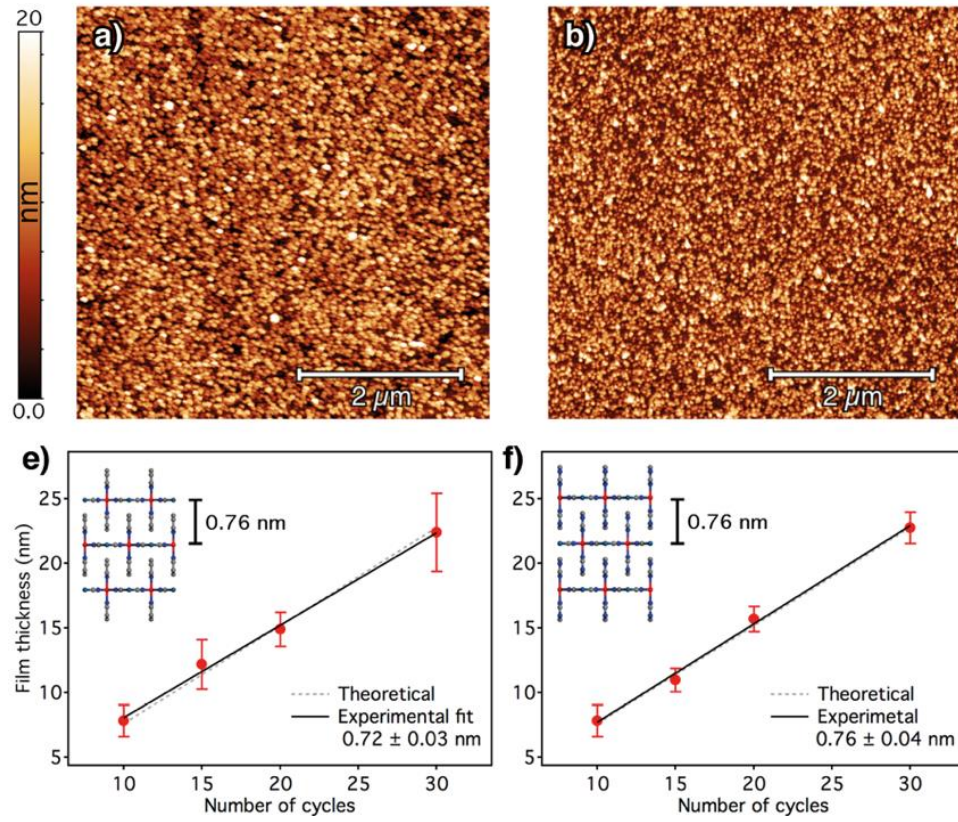
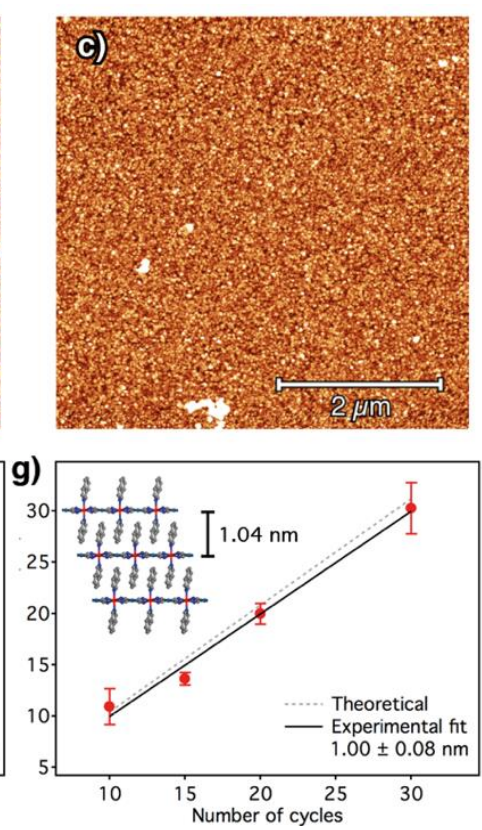

Figure 6. Surface morphology and thickness analysis of $\left[\mathrm{Fe}(\mathbf{L})_{2}\left\{\mathrm{Pt}(\mathrm{CN})_{4}\right\}\right]$ ultrathin films. (Top) $5 \times 5 \mu \mathrm{m}^{2}$ AFM topography images of 7 cycles samples of $L=p y(a)$, pym (b) and isoq (c). (Bottom) Evolution of film thickness with the number of cycles for samples of $L=p y(e)$, pym (f) and isoq $(\mathrm{g})$. Experimental thickness values were obtained from height distributions extracted from AFM images of manually scratched samples. We averaged at least three measurements from at least two samples, error bars correspond to standard deviations. Fits of the film thickness data versus the number of cycles (black lines) yield the experimental interlayer distances which are indicated in the legend of each graph. These experimental values are in excellent agreement with the theoretical values (dashed grey lines) extracted from the crystal structures shown as insets. 
diffraction peaks. This corresponds to a parallel disposition of the metal-cyanide layers with respect to the substrate, which is then nor$\mathrm{mal}$ to the $\mathrm{b}$ crystallographic axis. Hence, no (0k0) peaks are visible in the in-plane diffractograms, which presents intense (h00), (001) and (hol) peaks. Consistent with previous reports, ${ }^{40}$ the metal-cyanide planes do not grow perfectly parallel to the substrate but are slanted to some extent, as indicated by the presence of the (111) and (311) peaks in the in-plane profile of $L=$ py (Figure 5a), and the (110), (111), (112), (221) and (151) [which is indistinguishable from (202)] peaks in the in-plane diffractogram of $L=$ pym (Figure $\boldsymbol{5 b}$ ). This slight plane tilt in the metal-cyanide layers disposition would also explain the appearance of a small (111) peak in the outof-plane profile for $\mathrm{L}=$ py and a significant (110) peak in the case of $\mathrm{L}=$ pym due to its considerable intensity relative to the rest of the $(0 \mathrm{k} 0)$ peaks. On the other hand, the elucidation of the crystalline orientation of $\mathrm{L}=$ isoq films is expected to be more complex due to the corrugated nature of the metal-cyanide layers and the lower symmetry (triclinic versus orthorhombic) of the $\left[\mathrm{Fe}(\text { isoq })_{2}\left\{\mathrm{Pt}(\mathrm{CN})_{4}\right\}\right]$ system observed in the crystalline material (CCDC 1910991). Nevertheless, the disposition of this $2 \mathrm{D} \mathrm{Fe} \mathrm{F}^{\mathrm{II}}$ - $\mathrm{HCP}$ with respect to the substrate is equivalent to the other two compounds. As visible in Figure $\mathbf{5 c}$, the out-of-plane profile features intense (001) peaks, the (001) and (002) reflections are also present in the in-plane diffractogram but their intensity is much weaker and the (002) signal is hardly distinguishable from the (110) contribution to the peak. All this along with the rest of the diffraction peaks that appear in the inplane profile is consistent with the isoq linkers being normal to the surface of the substrate with the corrugated metal cyanide layers laying along the same surface. Ultimately, GIXRD shows that our ultrathin films of $2 \mathrm{D} \mathrm{Fe}{ }^{\text {II }}$-HCPs systems are crystalline and preferentially oriented with respect to the Au substrate. This is imposed by the py-SH SAM which binds the axial L ligands thanks to $\pi-\pi$ interactions between their aromatic rings, hence directing the growth of the $2 \mathrm{D} \mathrm{Fe}^{\mathrm{II}}$-HCPs perpendicular to the substrate.

The correspondence of film thickness and surface morphology with the number of immersion cycles was analyzed with AFM. Topography images shown in Figure 6 and Figure SI8 reveal a continuous surface for all cases regardless of the number of cycles or the particular 2D Fe $\mathrm{II}^{\mathrm{II}} \mathrm{HCPs}$ for any of the micrometric areas analyzed (up to $10 \times 10 \mu \mathrm{m}^{2}$ ). This is consistent with a full coverage of the substrates by $2 \mathrm{D} \mathrm{Fe} \mathrm{II}^{\mathrm{II}}$-HCPs films over these areas. The smoothness of the films was further studied by relating the surface roughness with the number of immersion cycles. Surface root mean square (RMS) roughness values (Figure SI9) estimated from topographic AFM $1 \times 1 \mu \mathrm{m}^{2}$ images, also roughly follows a linear trend with the number of immersion cycles scaling from $\sim 1$ to $\sim 6 \mathrm{~nm}$. This corresponds to roughly 1 to 6-8 layers. Above 10 cycles RMS values reach a plateau in all cases. This roughness values are in the range of previously reported ultrathin films of similar thicknesses. ${ }^{34,4547}$ To further verify the sequential growth of the $2 \mathrm{D} \mathrm{Fe}{ }^{\mathrm{II}}-\mathrm{HCP}$ ultrathin films we correlated the number of cycles with film thicknesses measured by AFM after scratching film samples with a soft pointy tool. Consistent with the IRRAS study displayed in Figure 3, values increase linearly with the number of cycles, confirming that a constant amount of material is incorporated to the films with every immersion cycle. Furthermore, the slope of the fitted lines (Figure 6e-f) matches well with the respective layer thicknesses determined from bulk phase crystallographic structures. This data suggests that the growth process involves the deposition of an average of one crystallographic cell per immersion cycle in all cases.

Effect of pillaring linker on structural flexibility. After confirming the chemical purity and crystallinity of our $2 \mathrm{D} \mathrm{Fe} \mathrm{II}^{\mathrm{II}}$-HCPs ultrathin films, we set on to investigate if the gate opening behavior previously observed for $\left[\mathrm{Fe}(\mathrm{py})_{2}\left\{\mathrm{Pt}(\mathrm{CN})_{4}\right\}\right]$ ultrathin films could be affected by changes to the pillaring linker. ${ }^{40}$ In this phenomenon, a flexible framework reacts to the presence of a guest, which causes a structural modification. ${ }^{48}$ We set to study guest-uptake on $\left.[\mathrm{Fe} \text { (isoq) })_{2}\left\{\mathrm{Pt}(\mathrm{CN})_{4}\right\}\right]$ films anticipating a positive influence gas-uptake capacity because of its incremented interlayer distance with respect to the other two systems and the corrugated nature of its layers, which might allow additional framework flexibility. Specifically, the interlayer separation between the metal-cyanide planes in $\left[\mathrm{Fe}(\text { isoq })_{2}\left\{\mathrm{Pt}(\mathrm{CN})_{4}\right\}\right]$ is $37 \%$ larger than in $\left[\mathrm{Fe}(\mathrm{py})_{2}\left\{\mathrm{Pt}(\mathrm{CN})_{4}\right\}\right]$, which in principle should facilitate the vertical separation of the layers necessary for solvent insertion. The gate opening effect originally reported by Kitagawa and collaborators was ascribed to a nanosizing effect, because it was only observed in ultrathin films and not in thick films or bulk powders. ${ }^{40}$ In fact, we also observed a negligible solvent uptake in a bulk powder sample of $\left[\mathrm{Fe}(\text { isoq })_{2}\left\{\mathrm{Pt}(\mathrm{CN})_{4}\right\}\right]$, which did not undergo a significant change of its lattice parameters (Figure SI10). For thin films, we used equivalent ultrathin film samples with the same number of layers (30 immersion cycles) than the previously reported experiments, in order to make our results fully comparable with those. In similar fashion to other solvent adsorption measurements with flexible MOF thin films, ${ }^{49}$ we performed in-situ surface XRD guest-uptake experiments at beamline BL9 of DELTA synchrotron $(\lambda=0.8266 \AA$, room temperature) $){ }^{50}$ Out-of-plane diffractograms (scanning mode) were recorded for ultrathin film samples under a continuous flow of different solvent-He mixtures, using the set-up illustrated in Figure SI11. Solvent adsorption was denoted after observing a negative displacement of the (001) peaks, characteristic of a lattice expansion normal to the substrate plane that occurs with guest uptake in $2 \mathrm{D} \mathrm{Fe}{ }^{\mathrm{II}}-\mathrm{HCPs}$ systems. ${ }^{40}$
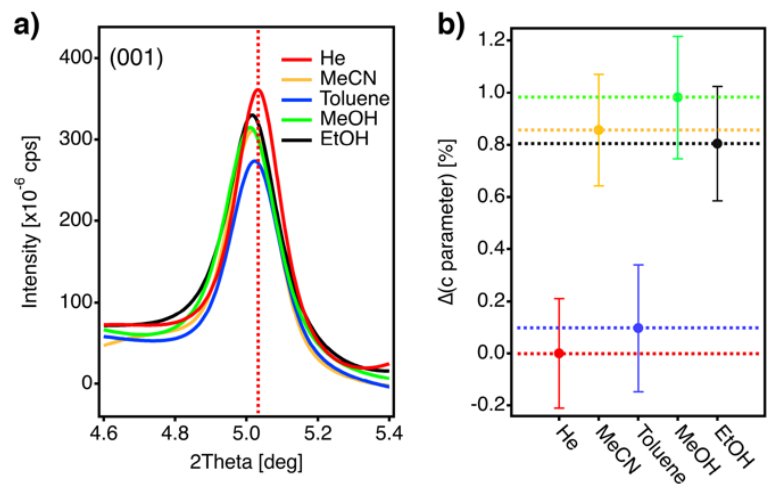

Figure 7. Lattice expansion due to solvent guest inclusion in $\left[\mathrm{Fe}(\text { isoq })_{2}\left\{\mathrm{Pt}(\mathrm{CN})_{4}\right\}\right]$ ultrathin films. a) Fittings of out-of-plane XRD profiles around the $(001)$ peak of a $\left[\mathrm{Fe}(\text { isoq })_{2}\left\{\mathrm{Pt}(\mathrm{CN})_{4}\right\}\right]$ ultrathin film (30-cycles) under different He-solvent atmospheres (He stands for a pure He without solvent). b) Percentage change in the c cell parameter as calculated from LeBail refinements of a $\left[\mathrm{Fe}(\mathrm{isoq})_{2}\left\{\mathrm{Pt}(\mathrm{CN})_{4}\right\}\right] \mathrm{ul}-$ trathin film (30-cycles) under different He-solvent mixtures. Error bars correspond to propagated standard deviations in the refinement of the unit cell parameter. 
Figure $7 \boldsymbol{a}$ shows the absolute displacement of the (001) peak under a maximum relative pressure $\left(\mathrm{P} / \mathrm{P}_{0}=1\right)$ of various solvent vapors and under pure $\mathrm{He}$ gas as reference. Figure $7 \boldsymbol{b}$ shows the evolution of the $c$ unit cell parameter as calculated from LeBail refinements of full out-of-plane diffractograms, featuring both (001) and (002) refinements peaks (Figure SI12 and Table SI6). Contrary to what we anticipated, the observed expansion effect was lower than that reported for $\left[\mathrm{Fe}(\mathrm{py})_{2}\left\{\mathrm{Pt}(\mathrm{CN})_{4}\right\}\right]$ ultrathin films. Our $\left[\mathrm{Fe}(\text { isoq })_{2}\left\{\mathrm{Pt}(\mathrm{CN})_{4}\right\}\right]$ films showed a maximum axial lattice expansion of only $0.98 \%$ under methanol while the expansion previously reported for $\left[\mathrm{Fe}(\mathrm{py})_{2}\left\{\mathrm{Pt}(\mathrm{CN})_{4}\right\}\right]$ ultrathin films under ethanol was of $1.6 \%$. We ascribe this milder expansion effect to a combination of two factors: first the stronger $\pi-\pi$ interactions between adjacent isoq axial ligands, which have two fused aromatic rings and hence a significantly higher number of contacts between atoms in the aromatic rings, in comparison to py that only has one single ring (Table SI2). This would hinder the expansion ability of the polymeric network to host the guest between the metal-cyanide layers, which according to Kitagawa's model would require to break the significantly stronger $\pi-\pi$ interactions between neighboring layers for the isoq case. Secondly, and despite the higher expansion in the interlayer spacing of $\left[\mathrm{Fe}(\text { isoq })_{2}\left\{\mathrm{Pt}(\mathrm{CN})_{4}\right\}\right]$ versus the other two $2 \mathrm{D}$ $\mathrm{Fe}^{\mathrm{II}}$-HCPs, the corrugation of the metal-cyanide layers together with the bulkier aromatic ligand blocks the gate opening phenomenon. In order to see the space initially accessible in the framework that would trigger the subsequent structural expansion with the solvent, we compared the available surface area (SA) of each $2 \mathrm{D} \mathrm{Fe}{ }^{\mathrm{II}}$-HCPs. Surprisingly, the simulated Connolly SA values follow the opposite tendency to the interlayer separation. Whilst $\left[\mathrm{Fe}(\mathrm{py})_{2}\left\{\mathrm{Pt}(\mathrm{CN})_{4}\right\}\right]$ and $\left[\mathrm{Fe}(\mathrm{pym})_{2}\left\{\mathrm{Pt}(\mathrm{CN})_{4}\right\}\right]$ have a SA value of $242.78 \AA^{2}$ and $239.18 \AA^{2}$ respectively, $\left[\mathrm{Fe}(\text { isoq })_{2}\left\{\mathrm{Pt}(\mathrm{CN})_{4}\right\}\right]$ has no accessible void space

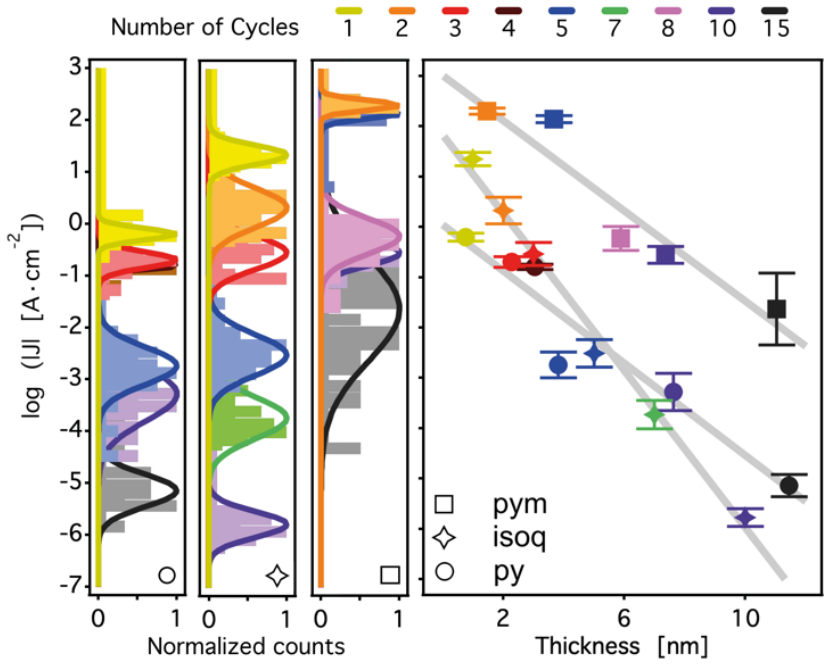

Figure 8. Electrical characterization of $2 \mathrm{D} \mathrm{Fe} \mathrm{e}^{I I}-\mathrm{HCP}$ ultrathin films. a) Dependence of the logarithm of the absolute value of the current density $(\log |\mathrm{J}|)$ measured at $0.1 \mathrm{~V}$ as a function of film thickness for $\left[\mathrm{Fe}(\mathrm{L})_{2}\left\{\mathrm{Pt}(\mathrm{CN})_{4}\right\}\right]$ films. $\mathrm{L}=$ py (circles) pym (squares) and isoq (pentagons). Maximum number of counts for each histogram has been normalized to 1 . Solid lines are gaussian fits to the data. b) Average log $|\mathrm{J}|$ values as a function of film thickness. Error bars correspond to the Gaussian width. Straight dashed lines are a linear fit to the data according to $\log \mathrm{J}=\log \mathrm{J}_{0}+\beta$ (thickness) $/ 2.303$. In all cases colors indicate the number of immersion cycles. available for the infiltration of guests (Figure SI13). Moreover, in our case the size of the guest molecule also seems to have a clear effect on the ability of $\left[\mathrm{Fe}(\text { isoq })_{2}\left\{\mathrm{Pt}(\mathrm{CN})_{4}\right\}\right]$ to vertically expand to accommodate them (Figure $7 \boldsymbol{b}$ ). The observed vertical cell expansion is only slightly smaller for ethanol and acetonitrile with respect to methanol. However, for toluene, which is considerably bulkier than the rest, the expansion is severely reduced to just $0.1 \%$.

Influence of film thickness and pillaring linker on vertical charge transport. In a previous work, we demonstrated that metal evaporation is inadequate to electrically contact $\left[\mathrm{Fe}(\mathrm{py})_{2}\left\{\mathrm{Pt}(\mathrm{CN})_{4}\right\}\right]$ films. ${ }^{39}$ Therefore, the use of softer contacting methods is imperative to study the electrical properties of $2 \mathrm{D} \mathrm{Fe} \mathrm{FI}^{\mathrm{II}}$ HCPs ultrathin films. In consonance with other studies involving MOF films, ${ }^{46,51-53}$ vertical charge transport was studied using liquid metal contacts. This methodology has also proven to be useful for studying the electronic characteristics of soft materials such as organic SAMs ${ }^{53,54}$ molecular wires, ${ }^{55}$ metal complexes, ${ }^{56}$ large biological complexes ${ }^{57}$ or metal-organic donor-acceptor systems. ${ }^{58-60} \mathrm{Be}$ sides its versatility and its compatibility with ambient conditions, ${ }^{61}$ it avoids the risk of damaging the soft film of interest which could occur with of conventional metallic top contact evaporation. ${ }^{62}$

We studied the electron transport characteristics of our films nanostructured on SAM-functionalized Au surfaces by using py-S-Au // $\left[\mathrm{Fe}(\mathrm{L})_{2}\left\{\mathrm{Pt}(\mathrm{CN})_{4}\right\}\right] / / \mathrm{Ga}_{2} \mathrm{O}_{3} / \mathrm{EGaIn}(\mathrm{EGaIn}=$ gallium-indium eutectic) liquid contact junctions. First, a micrometric Ga-In eutectic droplet was carefully brought into contact with the 2D Fe ${ }^{\mathrm{II}}$-HCP ultrathin films. Next, the area of the contact (ranging from $\sim 3200$ to $\sim 12000 \mu \mathrm{m}^{2}$ ) was determined with the aid of a CCD camera and the current densities (J) of the molecular junctions measured as a function of the voltage (V). See SII and Figures SI15-SI17 for details about the used method and experimental setup. Semilog J-V characteristics were obtained by averaging hundreds of $\mathrm{J}-\mathrm{V}$ curves measured for multiple contacts at different positions across the surface of each $2 \mathrm{D} \mathrm{Fe}{ }^{\mathrm{II}}$-HCP film samples after 1-11 immersion cycles (thickness $<15 \mathrm{~nm}$ ). As visible in Figure SII8, the curves are symmetric within the testing window, scale down in conductivity for increasing film thickness and display the non-linear current versus bias dependence expected for a semiconductor. Current density histograms at a given voltage were calculated from the measured $|J( \pm V)|$. The experimental variations, which are likely due to the presence of small local variation on thickness, roughness or structure and/or to errors on the estimation of the droplet diameter, result in roughly log-normally distributed J values. Figure 8 shows the average $\log \mathrm{J}$ values as function of the number of cycles.

Table 1. Attenuation factors $(\beta), J_{0}$ and interlayer distances $(d)$ for $\left[\mathrm{Fe}(\mathrm{L})_{2}\left\{\mathrm{Pt}(\mathrm{CN})_{4}\right\}\right]$ ultrathin films.

\begin{tabular}{llll}
\hline $\mathrm{L}$ & $\beta\left[\AA^{-1}\right]$ & $\mathrm{J}_{0}\left[\mathrm{~A} \cdot \mathrm{cm}^{-2}\right]$ & $\mathrm{d}[\AA]$ \\
\hline py & 0.035 & 0.09 & 7.63 \\
pym & 0.033 & 3.08 & 7.56 \\
isoq & 0.079 & 1.87 & 10.4 \\
\hline
\end{tabular}

According to the literature, the tunneling mechanism is probably inadequate to describe charge transport across $2 \mathrm{D} \mathrm{Fe}{ }^{\mathrm{II}}$ HCPs and a multistep electron/hole hopping mechanism between redox sites is likely to be operative instead. ${ }^{63}$ However, analogously 
to what is customary for metal-molecule-metal junctions, ${ }^{64}$ these values were fitted to the following equation:

$$
\mathrm{J}=\mathrm{J}_{0} e^{-\beta \mathrm{T}}
$$

We used a linear fit of $\log \mathrm{J}$ vs film thickness $(\mathrm{T}=\mathrm{d} \cdot \mathrm{num}$ ber of cycles) at a specific voltage $(0.1 \mathrm{~V})$ to extract the attenuation length $(\beta)$; which is intrinsic to the electronic properties of the film and the contact current density $\mathrm{J}_{0}$; a factor that accounts for the interfaces between the film $\left(\left[\mathrm{Fe}(\mathrm{L})_{2}\left\{\mathrm{Pt}(\mathrm{CN})_{4}\right\}\right]\right)$ and the electrodes (py-S-functionalized $\mathrm{Au}$ and $\mathrm{Ga}_{2} \mathrm{O}_{3} / \mathrm{EGaIn}$ ). $\beta$ values in the $>0.1-1$ $\AA^{-1}$ range account for a strong dependence of resistance with film thickness, which is indicative of a tunneling regime. If there is a weaker dependence, the $\beta$ value is lower than $0.1 \AA^{-1}$ which is usually attributed to a hopping regime. A transition between both regimes has been observed around this $\beta$ value when varying the length of conjugated molecular wires ${ }^{65-67}$ as well as in molecular wires of coordination complexes. ${ }^{68}$ However, no shift in transport regimes has ever been observed in MOF thin films. ${ }^{46,51,52}$ For our $\left[\mathrm{Fe}(\mathrm{L})_{2}\left\{\mathrm{Pt}(\mathrm{CN})_{4}\right\}\right]$ ultrathin films, the data can be fitted to a single straight line indicating a unique transport mechanism without any regime transition. As shown in Table 1, the obtained attenuation factors $\beta$ correspond to ca. $0.03-0.08 \AA^{-1}$. These values are close to those reported for other conjugated organic molecular wires ${ }^{67,69}$ but are well above those observed in some metal-organic molecular wires ${ }^{56,68,70-72}$ and $3 \mathrm{D}$ coordination polymers. ${ }^{51}$ This is probably the result of the absence of covalent bonding between adjacent metalcyanide layers. Supramolecular $\pi-\pi$ interactions feebly contribute to electron delocalization and thus hinder electron hopping between metal centers. Similar $\beta$ values $\left(0.12 \AA^{-1}\right)$ were reported for NASF-1, a 2D CP formed by grid-like layers $(\mathrm{d}=9.3 \AA)$ of $\mathrm{Co}^{\mathrm{II}}$-tetracarboxylate porphyrins interconnected by $\mathrm{Cu}^{\mathrm{II}}$ ions and vertically stacked thanks to the $\pi$ - $\pi$ interactions between axial py ligands. ${ }^{46,73}$ As already anticipated for the structural response to guest atmosphere, differences in the pillaring ligand are also reflected in the electronic transport. Along the $\left[\mathrm{Fe}(\mathrm{L})_{2}\left\{\mathrm{Pt}(\mathrm{CN})_{4}\right\}\right]$ series, the larger interlayer distance $(d)$ mediated by isoq disfavors vertical charge transport and results in a higher $\beta$ value for the isoq derivative in spite of the stronger supramolecular interactions between layers. In turn, the py and pym analogues share similar interlayer distances and feature similar $\beta$ values. It is worth noting that, despite all $2 \mathrm{D} \mathrm{Fe}^{\mathrm{II}}-\mathrm{HCPs}$ being bond to the $\mathrm{Au}$ surface in an equivalent way through the py-SH SAM, at the time of junction formation they expose different interfacing groups toward the $\mathrm{Ga}_{2} \mathrm{O}_{3} / \mathrm{EGaIn}$ droplet that contribute differently to Jo. Within the series, $\mathrm{L}=$ pym with a donor heteroatom, displays the stronger interaction with the metallic top contact and thus yields a higher $\mathrm{J}_{0}$ value. ${ }^{7476}$ This further highlights the importance of the axial ligand in out-of-plane charge transport processes involving 2D CPs.

\section{CONCLUSIONS}

In conclusion, our fully automatized LPE procedure under an inert atmosphere allowed us to produce high quality ultrathin films (thickness $<30 \mathrm{~nm}$ ) of a family of $2 \mathrm{D} \mathrm{Fe} \mathrm{F}^{\mathrm{II}}-\mathrm{HCPs}$. The close examination of the axial ligand effect on out-of-plane film expansion under rich solvent atmospheres with in-situ surface XRD, suggests that this phenomenon can be blocked by increasing the strength of the $\pi-\pi$ interactions between neighboring layers. Therefore, the previously observed gate opening behavior cannot be only attributed to a reduction in film thickness below a critical value. The accessible surface area and strength of supramolecular interactions between consecutive layers, both controlled by the pillaring linker, are also relevant to this phenomenon. Moreover, the analysis of the interlayer charge transport of our films using liquid metal top contacts revealed a dominant hopping regime between redox metal centers. This process is also heavily influenced by the axial linker that not only affects the capacity of the film to transport current but also allows the engineering of film-electrode resistance. This type of study is unprecedented in SCO CPs and contributes to the perspective integration of these materials into the reign of electronics. However distant, this scenario will involve the manipulation of charge transport properties of extended solids nanostructured on surfaces through their SCO properties. On the other hand, from the point of view of nanofabrication, the high degree of control and versatility of advanced bottom-up techniques such as LPE, could enable the formation of heterostructures of different $2 \mathrm{D} \mathrm{Fe} \mathrm{F}^{\mathrm{II}}-\mathrm{HCPs}$. We are currently exploring this possibility to produce hybrid films with structural and electronic properties tailored by chemical design.

\section{ASSOCIATED CONTENT}

\section{Supporting Information.}

Figures SI1-SI18, Tables SI1-SI6 and further details on the electrical characterization of the films.

This material is available free of charge via the Internet at http://pubs.acs.org.

\section{AUTHOR INFORMATION}

\section{Corresponding Author}

*e-mail: sergio.tatay@uv.es; carlos.marti@uv.es.

\section{Present Addresses}

a Unité Mixte de Physique, CNRS, Thales, University Paris Sud, Université Paris-Saclay, 91767 Palaiseau, France.

\section{Author Contributions}

All authors have given approval to the final version of the manuscript.

\section{Notes}

The authors declare no competing financial interest.

\section{ACKNOWLEDGMENT}

This work was supported by the EU (ERC Stg Chem-fs-MOF 714122), the Spanish MINECO (Unit of Excellence María de Maeztu MDM2015-0538, CTQ2017-83486-P and CTQ2016-78341-P) and the Generalitat Valenciana (PROMETEO/2016/147). C.M.-G. and S.T. thank the Spanish MINECO for their Ramón y Cajal fellowships (RYC-201210894 and RYC-2016-19817). V.R.-G. thanks the Spanish MECD for his FPU (FPU13/03203) predoctoral fellowship. G.E-A. thanks the Generalitat Valenciana for his Santiago Grisolía fellowship (GRISOLIA/2015/007). M.G. thanks the European Union Horizon 2020 Marie Curie Actions under the project SPIN2D (H2020/2014659378). We gratefully acknowledge DELTA Dortmund synchrotron for allocation of beamtime at beamline BL9. The atomic spectroscopy section of SCSIE (Universitat de València) is gratefully acknowledged for the Elemental CHNSO analysis. We also thank Julián Heredero Calero and Ángel Lopéz-Muñoz for their technical support.

\section{REFERENCES}


(1) Allendorf, M. D.; Schwartzberg, A.; Stavila, V.; Talin, A. A. A Roadmap to Implementing Metal-Organic Frameworks in Electronic Devices: Challenges and Critical Directions. Chem. Eur. J. 2011, 17 (41), 11372-11388.

(2) Falcaro, P.; Ricco, R.; Doherty, C. M.; Liang, K.; Hill, A. J.; Styles, M. J. MOF Positioning Technology and Device Fabrication. Chem. Soc. Rev. 2014, 43 (16), 5513-5560.

(3) Zhao, W.; Peng, J.; Wang, W.; Liu, S.; Zhao, Q.; Huang, W. Ultrathin Two-Dimensional Metal-Organic Framework Nanosheets for Functional Electronic Devices. Coord. Chem. Rev. 2018, 377, 4463.

(4) Zacher, D.; Shekhah, O.; Wöll, C.; Fischer, R. A. Thin Films of Metal-Organic Frameworks. Chem. Soc. Rev. 2009, 38 (5), 14181429.

(5) Bétard, A.; Fischer, R. A. Metal-Organic Framework Thin Films: From Fundamentals to Applications. Chem. Rev. 2012, 112 (2), 1055-1083.

(6) Sakamoto, R.; Takada, K.; Pal, T.; Maeda, H.; Kambe, T.; Nishihara, H. Coordination Nanosheets (CONASHs): Strategies, Structures and Functions. Chem. Commun. 2017, 53 (43), 57815801.

(7) Ashworth, D. J.; Foster, J. A. Metal-Organic Framework Nanosheets (MONs): a New Dimension in Materials Chemistry. J. Mater. Chem. A 2018, 6 (34), 16292-16307.

(8) Zhao, M.; Huang, Y.; Peng, Y.; Huang, Z.; Ma, Q.; Zhang, H. Two-Dimensional Metal-Organic Framework Nanosheets: Synthesis and Applications. Chem. Soc. Rev. 2018, 47 (16), 6267-6295.

(9) Zacher, D.; Schmid, R.; Wöll, C.; Fischer, R. A. Surface Chemistry of Metal-Organic Frameworks at the Liquid-Solid Interface. Angew. Chem. Int. Ed. 2011, 50 (1), 176-199.

(10) Gros, C. R.; Peprah, M. K.; Hosterman, B. D.; Brinzari, T. V.; Quintero, P. A.; Sendova, M.; Meisel, M. W.; Talham, D. R. Light-Induced Magnetization Changes in a Coordination Polymer Heterostructure of a Prussian Blue Analogue and a Hofmann-Like Fe(II) Spin Crossover Compound. J. Am. Chem. Soc. 2014, 136 (28), 98469849.

(11) Shi, S.; Schmerber, G.; Arabski, J.; Beaufrand, J. B.; Kim, D. J.; Boukari, S.; Bowen, M.; Kemp, N. T.; Viart, N.; Rogez, G.; Beaurepaire, E.; Aubriet, H.; Petersen, J.; Becker, C.; Ruch, D. Study of Molecular Spin-Crossover Complex Fe(Phen) ${ }_{2}(\mathrm{Ncs})_{2}$ Thin Films. Appl. Phys. Lett. 2009, 95 (4), 043303.

(12) Gruber, M.; Davesne, V.; Bowen, M.; Boukari, S.; Beaurepaire, E.; Wulfhekel, W.; Miyamachi, T. Spin State of Spin-Crossover Complexes: From Single Molecules to Ultrathin Films. Phys. Rev. B 2014, 89 (19), 195415-195419.

(13) Zhang, X.; Costa, P. S.; Hooper, J.; Miller, D. P.; N'Diaye, A. T.; Beniwal, S.; Jiang, X.; Yin, Y.; Rosa, P.; Routaboul, L.; Gonidec, M.; Poggini, L.; Braunstein, P.; Doudin, B.; Xu, X.; Enders, A.; Zurek, E.; Dowben, P. A. Locking and Unlocking the Molecular Spin Crossover Transition. Adv. Mater. 2017, 29 (39), 1702257-10.

(14) Poggini, L.; Milek, M.; Londi, G.; Naim, A.; Poneti, G.; Squillantini, L.; Magnani, A.; Totti, F.; Rosa, P.; Khusniyarov, M. M.; Mannini, M. Room Temperature Control of Spin States in a Thin Film of a Photochromic Iron( Ii) Complex. Mater. Horiz. 2018, 5 (3), 506513.

(15) Kipgen, L.; Bernien, M.; Ossinger, S.; Nickel, F.; Britton, A. J.; Arruda, L. M.; Naggert, H.; Luo, C.; Lotze, C.; Ryll, H.; Radu, F.; Schierle, E.; Weschke, E.; Tuczek, F.; Kuch, W. Evolution of Cooperativity in the Spin Transition of an Iron(II) Complex on a Graphite Surface. Nat. Commun. 2018, 9 (1), 2984.

(16) Gütlich, P.; Hauser, A.; Spiering, H. Thermal and Optical Switching of Iron(II) Complexes. Angew. Chem.; Int. Ed. Engl. 1994, 33 (20), 2024-2054.

(17) Real, J. A.; Gaspar, A. B.; Niel, V.; Muñoz, M. C. Communication Between Iron(II) Building Blocks in Cooperative Spin Transition Phenomena. Coord. Chem. Rev. 2003, 236 (1-2), 121-141.

(18) Garcia, Y.; Niel, V.; Muñoz, M. C.; Real, J. A. Spin Crossover in 1D, 2D and 3D Polymeric Fe(II) Networks. In Spin Crossover in
Transition Metal Compounds I; Gütlich, P., Goodwin, H. A., Eds.; Topics in Current Chemistry; Springer Berlin Heidelberg: Berlin, Heidelberg, 2004; Vol. 233, pp 229-257.

(19) Real, J. A.; Gaspar, A. B.; Muñoz, M. C. Thermal, Pressure and Light Switchable Spin-Crossover Materials. Dalton Trans. 2005, 64 (12), 2062-18.

(20) Gütlich, P.; Gaspar, A. B.; Garcia, Y. Spin State Switching in Iron Coordination Compounds. Beilstein J. Org. Chem. 2013, 9 (1), 342-391.

(21) Brooker, S. Spin Crossover with Thermal Hysteresis: Practicalities and Lessons Learnt. Chem. Soc. Rev. 2015, 44 (10), 2880 2892.

(22) Kumar, K. S.; Ruben, M. Emerging Trends in Spin Crossover (SCO) Based Functional Materials and Devices. Coord. Chem. Rev. 2017, 346, 176-205.

(23) Rotaru, A.; Dugay, J.; Tan, R. P.; Gural'skiy, I. A.; Salmon, L.; Demont, P.; Carrey, J.; Molnár, G.; Respaud, M.; Bousseksou, A. Nano-Electromanipulation of Spin Crossover Nanorods: Towards Switchable Nanoelectronic Devices. Adv. Mater. 2013, 25 (12), 1745-1749.

(24) Devid, E. J.; Martinho, P. N.; Kamalakar, M. V.; Salitros, I.; Prendergast, Ú.; Dayen, J.-F.; Meded, V.; Lemma, T.; GonzálezPrieto, R.; Evers, F.; Keyes, T. E.; Ruben, M.; Doudin, B.; van der Molen, S. J. Spin Transition in Arrays of Gold Nanoparticles and Spin Crossover Molecules. ACS Nano 2015, 9 (4), 4496-4507.

(25) Aragonès, A. C.; Aravena, D.; Cerdá, J. I.; Acís-Castillo, Z.; Li, H.; Real, J. A.; Sanz, F.; Hihath, J.; Ruiz, E.; Díez-Pérez, I. Large Conductance Switching in a Single-Molecule Device Through Room Temperature Spin-Dependent Transport. Nano Lett. 2016, 16 (1), 218-226.

(26) Holovchenko, A.; Dugay, J.; Giménez-Marqués, M.; TorresCavanillas, R.; Coronado, E.; van der Zant, H. S. J. Near Room-Temperature Memory Devices Based on Hybrid Spin-Crossover@SiO 2 Nanoparticles Coupled to Single-Layer Graphene Nanoelectrodes. Adv. Mater. 2016, 28, 7228-7233.

(27) Jasper-Toennies, T.; Gruber, M.; Karan, S.; Jacob, H.; Tuczek, F.; Berndt, R. Robust and Selective Switching of an FeIIISpin-Crossover Compound on $\mathrm{Cu} 2 \mathrm{~N} / \mathrm{Cu}(100)$ with Memristance Behavior. Nano Lett. 2017, 17 (11), 6613-6619.

(28) Molnár, G.; Rat, S.; Salmon, L.; Nicolazzi, W.; Bousseksou, A. Spin Crossover Nanomaterials: From Fundamental Concepts to Devices. Adv. Mater. 2017, 30 (5), 1703862-23.

(29) Lefter, C.; Davesne, V.; Salmon, L.; Molnár, G.; Demont, P.; Rotaru, A.; Bousseksou, A. Charge Transport and Electrical Properties of Spin Crossover Materials: Towards Nanoelectronic and Spintronic Devices. Magnetochemistry 2016, 2 (1), 18-19.

(30) Mason, W. R., III; Chemical, H. G. J. O. T. A.; 1968. Electronic Structures of Square-Planar Complexes. J. Am. Chem. Soc. 1968, 90 (21), 5721-5729.

(31) Otsubo, K.; Haraguchi, T.; Kitagawa, H. Nanoscale Crystalline Architectures of Hofmann-Type Metal-Organic Frameworks. Coord. Chem. Rev. 2017, 346, 123-138.

(32) Muñoz, M. C.; Real, J. A. Thermo-, Piezo-, Photo- and ChemoSwitchable Spin Crossover Iron(II)-Metallocyanate Based Coordination Polymers. Coord. Chem. Rev. 2011, 255 (17-18), 2068-2093.

(33) Bell, C. M.; Arendt, M. F.; Gomez, L.; Schmehl, R. H.; Mallouk, T. E. Growth of Lamellar Hofmann Clathrate Films by Sequential Ligand Exchange Reactions: Assembling a Coordination Solid One Layer at a Time. J. Am. Chem. Soc. 1994, 116 (18), 8374-8375.

(34) Bartual-Murgui, C.; Salmon, L.; Akou, A.; Thibault, C.; Molnár, G.; Mahfoud, T.; Sekkat, Z.; Real, J. A.; Bousseksou, A. High Quality Nano-Patterned Thin Films of the Coordination Compound $\left\{\mathrm{Fe}\left(\right.\right.$ Pyrazine) $\left.\left[\mathrm{Pt}(\mathrm{CN})_{4}\right]\right\}$ Deposited Layer-by-Layer. New J. Chem. 2011, 35 (10), 2089-2094.

(35) Haraguchi, T.; Otsubo, K.; Sakata, O.; Fujiwara, A.; Kitagawa, H. Remarkable Lattice Shrinkage in Highly Oriented Crystalline Three-Dimensional Metal-Organic Framework Thin Films. Inorg. Chem. 2015, 54 (24), 11593-11595. 
(36) Cobo, S.; Molnár, G.; Real, J. A.; Bousseksou, A. Multilayer Sequential Assembly of Thin Films That Display Room-Temperature Spin Crossover with Hysteresis. Angew. Chem. Int. Ed. 2006, 45 (35), 5786-5789.

(37) Molnár, G.; Cobo, S.; Real, J. A.; Carcenac, F.; Daran, E.; Vieu, C.; Bousseksou, A. A Combined Top-Down/Bottom-Up Approach for the Nanoscale Patterning of Spin-Crossover Coordination Polymers. Adv. Mater. 2007, 19 (16), 2163-2167.

(38) Otsubo, K.; Haraguchi, T.; Sakata, O.; Fujiwara, A.; Kitagawa, H. Step-by-Step Fabrication of a Highly Oriented Crystalline ThreeDimensional Pillared-Layer-Type Metal-Organic Framework Thin Film Confirmed by Synchrotron X-Ray Diffraction. J. Am. Chem. Soc. 2012, 134 (23), 9605-9608.

(39) Rubio-Giménez, V.; Bartual-Murgui, C.; Galbiati, M.; NúñezLópez, A.; Castells-Gil, J.; Quinard, B.; Seneor, P.; Otero, E.; Ohresser, P.; Cantarero, A.; Coronado, E.; Real, J. A.; Mattana, R.; Tatay, S.; Martí-Gastaldo, C. Effect of Nanostructuration on the Spin Crossover Transition in Crystalline Ultrathin Films. Chem. Sci. 2019, 10 (14), 4038-4047.

(40) Sakaida, S.; Otsubo, K.; Sakata, O.; Song, C.; Fujiwara, A.; Takata, M.; Kitagawa, H. Crystalline Coordination Framework Endowed with Dynamic Gate-Opening Behaviour by Being Downsized to a Thin Film. Nat. Chem. 2016, 377-383.

(41) Roisnel, T.; Rodríquez-Carvajal, J. WinPLOTR: a Windows Tool for Powder Diffraction Pattern Analysis. Mater. Sci. Forum 2001, 378-381, 118-123.

(42) Nakamoto, K. Infrared and Raman Spectra of Inorganic and Coordination Compounds, 5 ed.; Wiley: Hoboken, USA, 2008.

(43) Agustí, G.; Ohtani, R.; Yoneda, K.; Gaspar, A. B.; Ohba, M.; Sánchez-Royo, J. F.; Muñoz, M. C.; Kitagawa, S.; Real, J. A. Oxidative Addition of Halogens on Open Metal Sites in a Microporous SpinCrossover Coordination Polymer. Angew. Chem. Int. Ed. 2009, 48 (47), 8944-8947.

(44) Mazalov, L. N.; Asanov, I. P.; Varnek, V. A. Study of Electronic Structure of Spin-Transition Complexes by XPS and Mössbauer Spectroscopy. J. Electron Spectrosc. Relat. Phenom. 1998, 96 (1-3), 209-214.

(45) Munuera, C.; Shekhah, O.; Wang, H.; Wöll, C.; Ocal, C. The Controlled Growth of Oriented Metal-Organic Frameworks on Functionalized Surfaces as Followed by Scanning Force Microscopy. Phys Chem Chem Phys 2008, 10 (48), 7257-7261.

(46) Rubio-Giménez, V.; Tatay, S.; Volatron, F.; Martínez-Casado, F. J.; Martí-Gastaldo, C.; Coronado, E. High-Quality Metal-Organic Framework Ultrathin Films for Electronically Active Interfaces. J. Am. Chem. Soc. 2016, 138 (8), 2576-2584.

(47) Lopes, M.; Quintero, C. M.; Hernández, E. M.; Velázquez, V.; Bartual-Murgui, C.; Nicolazzi, W.; Salmon, L.; Molnár, G.; Bousseksou, A. Atomic Force Microscopy and Near-Field Optical Imaging of a Spin Transition. Nanoscale 2013, 5 (17), 7762-7767.

(48) Haraguchi, T.; Otsubo, K.; Sakata, O.; Fujiwara, A.; Kitagawa, H. Guest-Induced Two-Way Structural Transformation in a Layered Metal-Organic Framework Thin Film. J. Am. Chem. Soc. 2016, 138 (51), 16787-16793.

(49) Wannapaiboon, S.; Schneemann, A.; Hante, I.; Tu, M.; Epp, K.; Semrau, A. L.; Sternemann, C.; Paulus, M.; Baxter, S. J.; Kieslich, G.; Fischer, R. A. Control of Structural Flexibility of Layered-Pillared Metal-Organic Frameworks Anchored at Surfaces. Nat. Commun. 2019, 1-10.

(50) Krywka, C.; Paulus, M.; Sternemann, C.; Volmer, M.; Remhof, A.; Nowak, G.; Nefedov, A.; Poter, B.; Spiegel, M.; Tolan, M. The New Diffractometer for Surface X-Ray Diffraction at Beamline BL9 of DELTA. J. Synchrotron Rad. 2006, 13, 8-13.

(51) Liu, J.; Wächter, T.; Irmler, A.; Weidler, P. G.; Gliemann, H.; Pauly, F.; Mugnaini, V.; Zharnikov, M.; Wöll, C. Electric Transport Properties of Surface-Anchored Metal-Organic Frameworks and the Effect of Ferrocene Loading. ACS Appl. Mater. Interfaces 2015, 7 (18), 9824-9830.

(52) Neumann, T.; Liu, J.; Wächter, T.; Friederich, P.; Symalla, F.; Welle, A.; Mugnaini, V.; Meded, V.; Zharnikov, M.; Wöll, C.; Wenzel,
W. Superexchange Charge Transport in Loaded Metal Organic Frameworks. ACS Nano 2016, 10 (7), 7085-7093.

(53) Chiechi, R. C.; Weiss, E. A.; Dickey, M. D.; Whitesides, G. M. Eutectic Gallium-Indium (EGaIn): a Moldable Liquid Metal for Electrical Characterization of Self-Assembled Monolayers. Angew. Chem. Int. Ed. 2008, 47 (1), 142-144.

(54) Nijhuis, C.; Reus, W.; Whitesides, G. Molecular Rectification in Metal-SAM-Metal Oxide-Metal Junctions. J. Am. Chem. Soc. 2009, 131 (49), 17814-17827.

(55) Fracasso, D.; Muglali, M. I.; Rohwerder, M.; Terfort, A.; Chiechi, R. C. Influence of an Atom in EGaIn/ $\mathrm{Ga}_{2} \mathrm{O}_{3}$ Tunneling Junctions Comprising Self-Assembled Monolayers. J. Phys. Chem. C 2013, 117 (21), 11367-11376.

(56) Tuccitto, N.; Ferri, V.; Cavazzini, M.; Quici, S.; Zhavnerko, G.; Licciardello, A.; Rampi, M. A. Highly Conductive |[Sim]|40-NmLong Molecular Wires|[Nbsp]|Assembled by Stepwise Incorporation of|[Nbsp]|Metal|[Nbsp]|Centres. Nat. Mater. 2009, 8 (1), $41-$ 46.

(57) Castañeda Ocampo, O. E.; Gordiichuk, P.; Catarci, S.; Gautier, D. A.; Herrmann, A.; Chiechi, R. C. Mechanism of Orientation-Dependent Asymmetric Charge Transport in Tunneling Junctions Comprising Photosystem I. J. Am. Chem. Soc. 2015, 137 (26), 84198427.

(58) Souto, M.; Yuan, L.; Morales, D. C.; Jiang, L.; Ratera, I.; Nijhuis, C. A.; Veciana, J. Tuning the Rectification Ratio by Changing the Electronic Nature (Open-Shell and Closed-Shell) in Donor-Acceptor Self-Assembled Monolayers. J. Am. Chem. Soc. 2017, 139 (12), 4262-4265.

(59) Gutiérrez, D.; Riera-Galindo, S.; Ajayakumar, M. R.; Veciana, J.; Rovira, C.; Mas-Torrent, M.; Crivillers, N. Self-Assembly of an Organic Radical Thin Film and Its Memory Function Investigated Using a Liquid-Metal Electrode. J. Phys. Chem. C 2018, 122 (31), 17784-17791.

(60) Laurans, M.; Dalla Francesca, K.; Volatron, F.; Izzet, G.; Guérin, D.; Vuillaume, D.; Lenfant, S.; Proust, A. Molecular Signature of Polyoxometalates in Electron Transport of Silicon-Based Molecular Junctions. Nanoscale 2018, 10 (36), 17156-17165.

(61) Barber, J. R.; Yoon, H. J.; Bowers, C. M.; Thuo, M. M.; Breiten, B.; Gooding, D. M.; Whitesides, G. M. Influence of Environment on the Measurement of Rates of Charge Transport Across AgTS/SAM//Ga203/EGaIn Junctions. Chem. Mater. 2014, 26 (13), 3938-3947.

(62) Wang, C.-H.; Su, C.-W.; Chan, S. W.; Fan, L.-J.; Chen, M.-C.; Yang, Y.-W. Damaging Effect of Hot Metal Atoms on Organic Semiconducting Films During Top Contact Formation. J. Phys. Chem. C 2015, 119 (26), 14593-14602.

(63) D'Alessandro, D. M. Exploiting Redox Activity in Metal-Organic Frameworks: Concepts, Trends and Perspectives. Chem. Commun. 2016, 52 (58), 8957-8971.

(64) Liu, H.; Wang, N.; Zhao, J.; Guo, Y.; Yin, X.; Boey, F. Y. C.; Zhang, H. Length-Dependent Conductance of Molecular Wires and Contact Resistance in Metal-Molecule-Metal Junctions. Chemphyschem 2008, 9 (10), 1416-1424.

(65) Choi, S.; Kim, B.; Frisbie, C. D. Electrical Resistance of Long Conjugated Molecular Wires. Science 2009, 320, 1482-1486.

(66) Lu, Q.; Liu, K.; Zhang, H.; Du, Z.; Wang, X.; Wang, F. From Tunneling to Hopping: a Comprehensive Investigation of Charge Transport Mechanism in Molecular Junctions Based on Oligo(PPhenylene Ethynylene)S. ACS Nano 2009, 3 (12), 3861-3868.

(67) Luo, L.; Choi, S. H.; Frisbie, C. D. Probing Hopping Conduction in Conjugated Molecular Wires Connected to Metal Electrodes. Chem. Mater. 2010, 23, 631-645.

(68) Bu, D.; Xiong, Y.; Tan, Y. N.; Meng, M.; Low, P. J.; Kuang, D.B.; Liu, C. Y. Understanding the Charge Transport Properties of Redox Active Metal-Organic Conjugated Wires. Chem. Sci. 2018, 9, 3438-3450.

(69) Kaliginedi, V.; Rudnev, A. V.; Moreno-García, P.; Baghernejad, M.; Huang, C.; Hong, W.; Wandlowski, T. Promising 
Anchoring Groups for Single-Molecule Conductance Measurements. Phys Chem Chem Phys 2014, 16 (43), 23529-23539.

(70) Sedghi, G.; García-Suárez, V. M.; Esdaile, L. J.; Anderson, H. L.; Lambert, C. J.; Martín, S.; Bethell, D.; Higgins, S. J.; Elliott, M.; Bennett, N.; Macdonald, J. E.; Nichols, R. J. Long-Range Electron Tunnelling in Oligo-Porphyrin Molecular Wires. Nat. Nanotech. 2011, 6 (8), 517-523.

(71) Sakamoto, R.; Wu, K.-H.; Matsuoka, R.; Maeda, H.; Nishihara, H. П-Conjugated Bis(Terpyridine)Metal Complex Molecular Wires. Chem. Soc. Rev. 2015, 44 (21), 7698-7714.

(72) Luo, L.; Benameur, A.; Brignou, P.; Choi, S. H.; Rigaut, S.; Frisbie, C. D. Length and Temperature Dependent Conduction of Ruthenium-Containing Redox-Active Molecular Wires. J. Phys. Chem. C 2011, 115 (40), 19955-19961.
(73) Makiura, R.; Motoyama, S.; Umemura, Y.; Yamanaka, H.; Sakata, 0.; Kitagawa, H. Surface Nano-Architecture of a Metal--Organic Framework. Nature Publishing Group 2010, 9 (7), 565-571.

(74) Yoon, H. J.; Shapiro, N. D.; Park, K. M.; Thuo, M. M.; Soh, S.; Whitesides, G. M. The Rate of Charge Tunneling Through Self-Assembled Monolayers Is Insensitive to Many Functional Group Substitutions. Angew. Chem. Int. Ed. 2012, 51 (19), 4658-4661.

(75) Bernasek, S. L. Can We Understand the Molecule in Molecular Electronics? Angew. Chem. Int. Ed. 2012, 51 (39), 9737-9738.

(76) Leary, E.; La Rosa, A.; lez, M. T. G. X.; Rubio-Bollinger, G.; t, N. X. S. A. X.; n, N. M. X. Incorporating Single Molecules Into Electrical Circuits. the Role of the Chemical Anchoring Group. Chem. Soc. Rev. 2015, 44, 920-942. 